\title{
De internationale hypospadieregistratie
}

\author{
Barbara B. M. Kortmann ${ }^{1}$ Fred van der Toorn ${ }^{2}$
}

Published online: 15 November 2016

(C) The Author(s) 2016. This article is available at SpringerLink with Open Access.

Samenvatting In 2009 startte de Nederlandse hypospadiestudie, met als doel factoren te ontrafelen die de kans op complicaties na hypospadiechirurgie beïnvloeden. Inmiddels is de tijd rijp om deze studie om te zetten in een internationale kwaliteitsregistratie.

Trefwoorden kinderurologie $\cdot$ hypospadiechirurgie complicaties $\cdot$ kwaliteitsregistratie $\cdot$ HOPE-score

\section{The International Hypospadias Registration}

Abstract In 2009 the Dutch Hypospadias study started with the goal to unravel the factors that influence the chance of complications. Now the time has come to transform this study into an international quality registration.

Keywords pediatric urology · hypospadias surgery · complications $\cdot$ quality registration $\cdot \mathrm{HOPE}$-score

\section{Introductie}

In 2009 is de Nederlandse hypospadiestudie gestart om de resultaten van hypospadiechirurgie in Nederland vast te stellen, teneinde de uitkomsten van hypospadiechirurgie zo mogelijk te verbeteren. De opzet werd eerder beschreven

dr. Barbara B. M. Kortmann

barbara.kortmann@radboudumc.nl

1 afdeling Kinderurologie, Radboud Amalia Kinderziekenhuis, Nijmegen, Nederland

2 afdeling Kinderurologie, Sophia Kinderziekenhuis, Rotterdam, Nederland in dit tijdschrift in maart 2013 [1]. Inmiddels zijn er ruim 1700 jongens met een hypospadie geïncludeerd en is de inclusie gesloten.

Met name bij de ernstiger vormen van hypospadie, gaat hypospadiechirurgie gepaard met een aanzienlijk percentage complicaties. Kinderen met een ernstige vorm van een hypospadie ondergaan in hun leven vaak meer dan één operatie [2]. Het doel van de Nederlandse hypospadiestudie is de factoren te ontrafelen die van invloed zijn op de uitkomst op de korte en de lange termijn. We hopen van elkaar te kunnen leren hoe we, waar mogelijk, minder complicaties en een betere cosmetiek verkrijgen.

In de studie worden de gegevens van de patiënt, de operatie, de eventuele complicaties en het cosmetisch resultaat door middel van foto's vastgelegd in een online database (www.nvukwaliteit.nl). Om de cosmetische uitkomst consistent te kunnen beoordelen, is de Hypospadias Objective Penile Evaluation-score of kortweg de HOPE-score ontwikkeld en gevalideerd [3]. Deze cosmetiekscore wordt bepaald door een panel van professionals die onafhankelijk van elkaar de geanonimiseerde fotoseries beoordeeld met behulp van referentiefoto's van 'normale' én niet-normale uitkomsten. Er wordt gekeken naar de volgende chirurgisch corrigeerbare factoren: positie meatus, vorm meatus, vorm glans, vorm huid en torsie/angulatie. Ook ouders kennen op een tienpuntsschaal een cijfer toe aan hun tevredenheid met het cosmetisch aspect vóór en na de operatie en geven in een vragenlijst hun oordeel over dezelfde items van de HOPE-score als de professionals en hoe de plasfunctie van hun kind is. Naast de kortetermijnfollow-up worden de jongens vervolgd op 5-, 10- en 15-jarige leeftijd.

De meeste (kinder)urologen in Nederland die hypospadieën opereren, hebben patiënten in de studie geïncludeerd, $\mathrm{al}$ is er een grote variatie. De operateurs krijgen met regelmaat terugkoppeling van hun inclusieaantallen en het fol- 
low-uppercentage. Jaarlijks ontvangen ze een rapport met de uitkomsten van hun eigen patiënten ten opzichte van de gemiddelde uitkomsten van hun eigen centrum en die van de hele Nederlandse groep.

Momenteel wordt er hard gewerkt aan de analyses van de kortetermijngegevens van de Nederlandse hypospadiestudie, met als doel prognostische factoren voor een goede uitkomst vast te stellen. Het complicatiepercentage tussen de verschillende operateurs toont een duidelijke variantie; multivariate analyse zal dan ook moeten uitwijzen of specifieke risicofactoren voor deze verschillen kunnen worden geïdentificeerd. Toch blijft het lastig, zelfs bij deze grote patiëntenaantallen, om een specifieke risicofactor vast te stellen: Stel dat een zekere chirurg weinig fistels na operatie heeft, waarbij wordt vermoed dat het type hechttechniek van die chirurg de gunstige factor is, dan weten we dit pas zeker als een andere chirurg met een hoger fistelpercentage dan de eerste chirurg, betere resultaten bereikt na overstappen op die mogelijk gunstiger hechttechniek.

Een panel van drie ervaren hypospadiechirurgen hebben, onafhankelijk van elkaar, alle pre- en postoperatieve fotoseries beoordeeld met behulp van de HOPE-score, en ook deze cosmetische uitkomsten kunnen binnenkort worden geanalyseerd. Verder zullen er video-opnames beschikbaar worden gesteld van de technieken die geassocieerd zijn met bijvoorbeeld de top 5 van de beste uitkomsten. Iedere deelnemende kinderuroloog kan dan na bestudering van deze best-practice video's zelf bepalen of hij/zij het nodig vindt om zijn/haar techniek aan te passen. Vervolgens is het uiteraard interessant om na te gaan of het aanpassen van de techniek resulteert in betere operatie-uitkomsten.

\section{Van studie naar registratie}

Zoals de naam al zegt: het betreft een studie. Voor deelname aan een studie is informed consent nodig van de ouders en niet alle ouders geven die. Het maken van foto's en/of het vastleggen van gegevens in een database (ook al zijn de data geanonimiseerd) schrikt ouders soms af. De combinatie van een complicatieregistratie, de fotoseries en de vragenlijsten zorgt wel voor een compleet beeld van de uitkomst van de hypospadieoperatie. Willen we volledige registratie van de uitkomsten van hypospadiechirurgie, dan moeten we álle uitkomsten van elke primaire hypospadieoperatie zo objectief mogelijk vastleggen. Dat kan als wordt overgegaan op een hypospadieregistratie. Voor registratie is geen informed consent nodig, denk aan de cystectomieregistratie van de NVU en de DICA-registraties van de Heelkunde.

\section{International Hypospadias Registration (IHR)}

Naar aanleiding van voordrachten op internationale congressen is er vanuit verschillende centra in Europa en Noord-Amerika interesse getoond voor de Dutch Hypospadias Study. Nooit eerder is zo'n grote groep hypospadiepatiënten prospectief vervolgd en de combinatie van complicatiegegevens en cosmetiekfotoseries is uniek. Daarom is het initiatief genomen om een International Hypospadias Registration op te zetten. Hiervoor wordt goeddeels de opzet gebruikt van de Nederlandse hypospadiestudie, met anonieme registratie van patiëntgegevens, type hypospadie, gebruikte operatietechniek, complicaties en flowmetrieresultaten. Optioneel zijn vragenlijsten voor ouders of patiënt en gestandaardiseerde foto's voor beoordeling van het cosmetische resultaat. Deelnemers ontvangen een verslag van hun eigen resultaten, de anonieme, gemiddelde resultaten van de totale groep deelnemers en de variatie in uitkomsten. De ingevoerde data blijven eigendom van de deelnemer en deze mag hierover zelf publiceren, maar ook gezamenlijk met andere (internationale) centra.

In het najaar 2015 heeft tijdens het gezamenlijk congres van de ESPU en onder andere de vereniging van Amerikaanse kinderurologen een eerste bijeenkomst plaatsgevonden met geïnteresseerden in de IHR van tien verschillende nationaliteiten en werd het IHR-steering committee gevormd. Hier werden ervaringen uitgewisseld op het gebied van complicatieregistratie bij hypospadiechirurgie. De Zweedse hypospadiechirurgen gebruiken al een landelijke complicatieregistratie op papier, die erg veel overeenkomsten heeft met de gegevens die vastgelegd worden in onze Nederlandse online database. Verder werden de zorgen besproken betreffende de controle op betrouwbaarheid van de ingevoerde gegevens. Het doel van de IHR is een optimaal betrouwbare verslaglegging van de uitkomsten van hypospadiechirurgie, met als doel de best practices bij hypospadiechirurgie vast te kunnen stellen. Betrouwbare data - die steekproefsgewijs worden geverifieerd - en een complete follow-up zijn hierbij cruciaal.

Het is de bedoeling om de uitkomsten van hypospadiechirurgie te verbeteren voor elke patiënt met een hypospadie, waar dan ook dit kind ter wereld komt. Het is niet de bedoeling dat de IHR een middel wordt om reclame te maken voor een specifiek centrum of chirurg, noch een machtsmiddel van zorgverzekeraar of overheidsinstantie. Het bleek dat er bij deze internationalisering allerlei nieuwe aspecten aan de orde kwamen op het gebied van organisatie, juridische afspraken, beveiliging van patiëntengegevens, overeenkomsten wat betreft de dataset, dataverificatie et cetera, waarvoor professionele hulp en financiering nodig is. De EAU Research Foundation (EAU-RF) heeft de logistieke capaciteit en de professionele ervaring voor een dergelijke internationale registratie. Er is dan ook het afgelopen 
jaar, in samenwerking met deze organisatie, hard gewerkt aan de ontwikkeling van de IHR. De Nederlandse opzet van de website is aangepast voor internationaal gebruik en heeft de inspirerende naam INSPIRE (INternational hypoSPadias REgistry) gekregen (www.hypospadiasregistry.org) $\mathrm{Er}$ is een deelnamecontract opgesteld en een plan voor digitale veiligheid en privacy gemaakt. Zo komt er bijvoorbeeld een sms-verificatie om in te kunnen loggen op de website.

De Nederlandse hypospadiestudie werd gefinancierd vanuit de kwaliteitsgelden van de Stichting Kwaliteitsgelden Medisch Specialisten (SKMS). Deelname aan de internationale registratie zal voor rekening van elk deelnemend centrum komen. Om deel te nemen aan de registratie is een lidmaatschap van de ESPU vereist en een minimum inclusieaantal van 20 hypospadieoperaties per chirurg of 40 per centrum per jaar. Voor het vastleggen van geanonimiseerde gegevens van een patiënt is geen informed consent nodig, voor vragenlijsten en het opslaan van foto's wel. Deelnemers zullen dan ook alle primaire hypospadieoperaties moeten registreren. Alle andere rechten en plichten worden vastgelegd in het deelnamecontract. Elke deelnemer zal dan nog in eigen land en ziekenhuis na moeten gaan of er conflicterende regelgeving is ten aanzien van deelname.

De verwachting is dat de Nederlandse centra nog dit jaar gebruik kunnen gaan maken van de nieuwe internationale registratie. Gezien de deelnamekosten en de administratieve last die deelname met zich meebrengt, zal deelname waarschijnlijk op vrijwillige basis plaatsvinden.
Door het principe van de drie P's (Prospective data-collection, Periodic evaluation and Practice change if necessary) zal de internationale evolutie van hypospadiechirurgie hopelijk versneld worden.

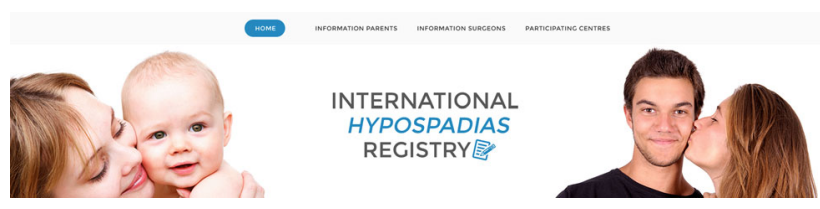

Open Access This article is distributed under the terms of the Creative Commons Attribution 4.0 International License (http:// creativecommons.org/licenses/by/4.0/), which permits unrestricted use, distribution, and reproduction in any medium, provided you give appropriate credit to the original author(s) and the source, provide a link to the Creative Commons license, and indicate if changes were made.

\section{Literatuur}

1. Toorn F van der, Jong TPVM de, Gier RPE de, et al. Nederlandse Hypospadie Studie: opzet en eerste resultaten. Ned Tijdschr Urol. 2013;2:57-63.

2. Nuininga JE, Gier RPE de, Verschuren R, Feitz WFJ. Long-term outcome of different types of 1-stage hypospadias repair. J Urol. 2005;174(4 Pt 2):1544-8.

3. Toorn F van der, Jong TPVM de, Gier RPE de, et al. Introducing the HOPE (Hypospadias Objective Penile Evaluation)-score: a validation study of an objective scoring system for evaluating cosmetic appearance in hypospadias patients. J Pediatr Urol. 2013;9(6 Pt B):1006-16.

dr. Barbara B.M. Kortmann kinderuroloog

drs. Fred van der Toorn kinderuroloog 